\title{
Editorial
}

\section{The curse of brand narcissism}

If you had to sum up accumulated wisdom about the heart of the successful brand, what would you say? Chances are, these three building blocks would loom large:

(1) Compared to other products, brands add value and deliver superior margins.

(2) To achieve brand success, we need deep consumer insight that translates into innovations that differentiate the brand in customers' eyes.

(3) To complete the circle, we also need cut-through, engaging marketing communications which influence consumer attitudes and behaviours in favour of the brand, thereby driving sales and loyalty.

Get these three right and fame and fortune will follow; or will they?

Viewed superficially, it is hard to see what could possibly be wrong with this holy trinity of added value, customerfocused innovation and differentiation, and communication. It lies at the heart of brand management - an essential and valuable process. Look a little closer, however, and you will find a dangerous disease lurking in the interstices of this theory - the disease of brand narcissism.

Brand narcissism uses all the same processes as brand management. It parades behind the same theories and the same rhetoric. It is excellent at masquerading as the real thing. But it leads us to precisely the opposite destination. Brands were invented as a means of creating win-win connections between companies and con- sumers, but brand narcissism asserts the needs of the brand over those of the customer. And it is more common than most of us dare to admit.

\section{THE LURE OF THE PREMIUM}

Let us start with a hallmark of successful brands: superior margins and premium prices. There are very good economic reasons why, historically, brands have delivered superior margins. The core model was pioneered in packaged goods many years ago. Superior margins are a by-product of economies of scale, continuous new product development and ongoing communication, which reinforce a continuing cycle of brand investment leading to repeat purchase, which in turn funds further investment. That is the wisdom the holy trinity tries to express.

But there is a fundamental difference between acknowledging the existence of brand premiums (a by-product of a superior economic model) and making brand premiums the purpose or goal of brand-building activities. That is when brand narcissism begins to take hold: when 'added value' gets corrupted into 'justifying a premium', and justifying this premium begins to edge out delivering superior value to customers. The widespread obsession with brand differentiation is one of the best examples of brand narcissism.

As Patrick Barwise and Seán Meehan $^{1}$ point out in their book 'Simply Better', this obsession with differentiation comes from looking at choice from the point of view of the brand rather than that of the consumer. 
To the seller, every consumer choice is an all-or-nothing affair: either the shopper buys my brand, or the shopper buys somebody else's brand. Survival depends on winning this contest, so anything that helps the brand stand out from the crowd is worthwhile.

To the shopper, however, the view is very different. There is endless choice, and most of the offers are pretty similar, so it is usually no great shakes which option is chosen. After all, any innovation that proves to be really valuable will be copied quickly by competitors fearful of losing market share.

What follows is simple but profound. Competitive pressures mean that all genuine value-creating innovations quickly get incorporated into category basics (or come to define a new category). Or, to put it another way, category basics are defined by the value that consumers are really looking for.

This outcome is almost the exact opposite of most theories of brand differentiation. What many marketers sneeringly refer to as mere 'table stakes' or 'hygiene factors' actually define value from the consumer perspective. And if something continues to differentiate the brand, it is almost certainly a difference that customers do not really care about. The real challenge, then, is not to differentiate brands, but continually to refine, deepen, extend and reinvent the category basics - the ultimate test of any organisation's ability to innovate.

(The phrase 'table stakes' was first used by Ted Levitt in 1980. ${ }^{2}$ Levitt's core argument was that specific product differentiators are continually competed away as customers' expectations rise. His conclusion was that differentiation - standing out from the crowd - can come from anything. What really matters is not any one differentiator in its own right, but the organisation's ability to keep on bringing such differentiators to market. What differentiates successful companies from the rest, he wrote, 'is how well they manage marketing, not just what is visibly marketed. It is the process, not just the product, that is uniquely differentiated.' As so often happens with seminal writings, however, a neat phrase — table stakes was subsequently lifted out of context and hijacked to support exactly the opposite argument. ${ }^{3}$ )

Dismissing the category basics as mere table stakes and then focusing on adding value in a different direction encourages executives to invest time and money doing things that customers do not care about, while they neglect to address things that customers do care about. $^{4}$

Worse, it sets the organisation on the road to cost-plus operations and mindsets, encouraging brand managers to over-engineer and increase complexity, always adding bells and whistles, but never streamlining and simplifying (because that would involve taking away differentiators). Even worse, because the added cost of this added value is compensated for by higher prices, such a strategy justifies increasingly bloated cost structures. In the process, it leaves the door open to no-frills challengers who focus on delivering the basics at a much lower price.

'Better brand building' is often posed as the brand manufacturers' answer to the rise of own-label and discount challengers. But the wrong approach to brand building - driven by the narcissistic quest to justify premium margins - is not the answer to this threat. It is one of the causes. Only very recently, for example, has Procter \& Gamble 
accepted that it needs to adopt targetcosting for some brands to address the needs of shoppers who opt for ownlabel products and discount channels.

\section{THE PITFALLS OF CUSTOMER FOCUS}

So what about the second pillar of the holy trinity, superior consumer focus and insight? Surely, we can never have too much customer focus?

In fact, in many companies 'customer focus' has degenerated into little more than politically correct rhetoric, a smoke screen for extended corporate navel gazing - the exact opposite of what it is supposed to be about. The slide into narcissism goes like this.

What is a customer? A customer is someone who buys what we sell. So when we say 'we are truly customer focused' what we actually mean is 'we are truly focused on what we sell' our brand. In this way attention shifts from the needs of the customer to the needs of the brand. Customer focus elides into brand focus, and brand focus is just another way for marketers to stare into the mirror of their own preoccupations.

It gets worse. If a customer is someone who buys what we make, then 'identifying and meeting customer needs' soon begins to mean something subtly different — 'identifying and meeting those customer needs that we are already good at meeting, profitably' - which is little more than profound product-centric conservatism dressed up in marketing-speak.

Of course, if there is a perfect fit between what the company makes and what consumers want, this is fine. But ultimately companies that take this approach become trapped by their brands, agonising endlessly over whether their brands can be stretched to accommodate changing customer needs. There is a big difference between companies that 'follow the customer' even when it involves significant changes to their operations, skills, product and service portfolios, and brand narcissists who invest their energies in persuading customers to continue following, and being 'loyal' to, their brands.

Faced with a lack of top-line growth, many companies turn to brand building as their saviour. Yet often, far from being the solution, narcissistic brand building is one of the causes, because it actually closes marketers' eyes to the real source of growth evolving customer needs.

\section{MARKETING SCHIZOPHRENIA}

The third trap lurking in our holy trinity is the evolution of brand building as a separate process undertaken by a separate group of specialist marketing professionals and their agencies.

The argument for this approach goes like this. While products are built in factories, brands are built in consumers' heads. In the end, the brand (all the associations and imagery that consumers connect to a particular product) resides in consumers' minds and influences choices from there. So therefore the main task of brand building is to manage the associations in consumers' minds via the communications process.

In this way, brand building quickly becomes a narrow communications activity focused on lodging the 'right' messages in target consumers' brains. Slowly but surely, this activity becomes divorced from the rest of the business. 
Once again, it gets worse as the company finds itself torn apart by two conflicting priorities:

(1) Identifying and meeting customer needs, to make the products the customer really wants.

(2) Issuing communications, the main aim of which is to change consumers' attitudes and behaviours in favour of the brand.

Priority number 1 revolves around getting the company to do what the customer wants it to do. Priority number 2 revolves around getting customers to do what the company wants them to do 'buy our brand!'. Put too much emphasis on the second process and brand narcissism quickly takes over.

There is more to this split personality than meets the eye. Marketing has its roots in an industrial age where the source of consumer value lay in the products companies produced. Companies then turned to their marketing communications to help realise this value by closing a sale. While the product addressed the consumer's (consumption) need, the marketing communication addressed the producer's (go-to-market) need.

This division of labour has lasted to this day, manifesting itself in the form of expensive brand wars where each advertiser seeks to grab the biggest share of 'consumer mind' - as if the mind in question had no needs or interests of its own, and was just a piece of inert property, the ownership of which is there to be contested. Far from creating win-wins between consumers and brands, the resulting cacophony - a direct by-product of brand building increasingly places consumers at loggerheads with marketers as they strive to edit the clutter of unhelpful marketing messages out of their lives. Recent research by Yankelovich in the USA, for example, reports that 60 per cent of US consumers now try to resist or avoid being exposed to marketing and advertising, and 69 per cent are interested in products and services that enable them to block, skip, or opt out of being exposed to advertising. ${ }^{5}$

The schizophrenic distinction between the value of 'the product' and the value of 'the communication' may have been tenable in the past. But in today's information age consumers do not only want quality products, they also want quality information - information which (like products) is reliable, easy to use, relevant to their needs and addresses both their consumption and their go-tomarket needs. By seeing marketing communications as a process by which the company changes consumer attitudes and behaviours to suit the needs of the brand, however, brand narcissism does not allow for this possibility.

As with own-label marketing and brand focus, the net effect is simple: brand narcissism leaves the market wide open to others - in this case media owners, pressure groups, regulators and consumer advocates — to fill the consumer's need for quality information and to build trust on this basis. Faced with declining trust in brands, "brand builders' respond with calls to redouble brand-building efforts. But, as with own-label marketing and the struggle to grow top-line sales, brand narcissism is not part of the solution. It is part of the problem.

\section{MARKETING'S STRATEGIC ROLE}

What do the following companies have in common: Toyota, Southwest 
Airlines, Ryan Air, Dell, Wal-Mart, Hennes \& Mauritz (H\&M), Inditex, Ikea, Aldi, Starbucks and Tesco? The answer is simple. In each of their industries, they have emerged as clear winners with performance that is not just marginally better than their peers, but outstandingly better.

Toyota, for example, is now so successful that its market capitalisation is greater than that of GM, Ford, DaimlerChrysler and Volkswagen combined. Likewise, Southwest Airlines has long been the only consistently profitable airline in the USA, with a market capitalisation larger than all of its competitors combined. Dell's sales and profits growth over the last ten years has been ten times greater than its computer industry peers. And, over the last decade, Wal-Mart's annual sales growth has been bigger than the total global sales of the Coca-Cola Company.

But now ask yourself this: 'How did these companies build such strong brands?' Was it because they excelled in a special black art called 'brand building'? No.

Of course they have worked hard to produce clearly identifiable brands, and they have communicated clearly and consistently - they have paid due attention to real brand management. But often their marketing communications have been low-key to the point of being prosaic and dull. Yet they and their brands are triumphant. Why?

Their secret (if there is ever one secret to success) is that they have all innovated, not at the relatively superficial level of communications strategy or product formulation and design, but at the more fundamental level of the business model, in order to deliver new breakthroughs in customer value (the 'basics' we talked about earlier) -
Toyota with lean production, Dell with its direct make-to-order system, Southwest with its point-to-point model, Aldi and Wal-Mart with their own variants of discounting, Inditex and H\&M with quick-response fashion supply, and so on. In other words, their brands have come to represent a new 'sweet spot' where superior economics (business model) connects with superior value for the consumer.

There is nothing new here. It is why early packaged goods brands were so successful, for example. In the days when packaged goods brands were first starting out, the main competition was, literally, commodities: goods of suspect quality that came in large crates or sacks marked, say, 'tea' or 'flour', where shopkeepers measured out specific quantities in response to consumers' requests. These commodities did not come with packaging, brand names, brand logos, advertising, brand personalities, USPs or any quality assurance. Brands (and the mechanisms of branding we are so familiar with today) helped to create a new virtuous spiral of quality, freshness, innovation, volume and value.

But that contest finished decades ago. Today, any and every product or service coming to market uses the mechanics of branding - design, advertising and so on - as a matter of course. These mechanisms are not a source of difference any more. They are standard practice. Brands, as defined by the mere use of these mechanisms, are the new commodity.

Marketers complain about being excluded from the board and not having a strategic role. But bells-andwhistles differentiation and innovation, and brand building as a separate communications activity with precious 
little to do with the rest of the business, simply create and reconfirm their marginal role. They are symptoms of brand narcissism at work.

\section{CONCLUSION}

Brands are - and always have been just the highly visible tip of complete business icebergs. The job of the brand is to encapsulate and articulate the value generated by the iceberg as a whole. Its superior margins and/or volume are a by-product of this iceberg's breadth and depth. The real challenge nowadays is the same as it always has been: how to build bigger icebergs by creating breakthroughs in consumer value. Branding may play a crucial role in crystallising this superior value, but it is not the source of this value. By focusing on the needs of the brand, rather than the needs of the consumer, brand narcissism stifles this quest.

Having strong brands is indeed crucial for every successful business. Brand management - consistent, well-targeted, clear communication is an essential skill. But the roots of brand narcissism lie elsewhere, in clients buffeted by competitive pressures seeking magic-bullet, short-cut, easy routes to success, and in agencies for whom pandering to this quest is a meal ticket.

Ultimately, brands are not built by a separate activity called 'brand building' any more than races are won by a separate activity called 'winning' or the tips of icebergs are made bigger by a specialist activity called 'tip building'.

The negative effects of brand narcissism include pitting the interests of the brand against those of the consumer (the quest to levy a premium and to use 'marketing' to organise consumer attitudes and behaviours around the needs of the brand), leaving gaps in the market for new forms of competition to attack (such as own-label marketing on the product front and pressure groups on the information front), stifling real innovation and growth, and marginalising marketers within firms.

In fact, many of the problems that brand manufacturers turn to brand building to solve can actually be laid, at least in part, at the door of brand narcissism. By severing the connection between 'superior economics' and 'superior consumer value' brand narcissism erodes the win-wins between consumers and companies that make great brands great. It is a medicine that makes the patient sick.

Brand narcissism is the enemy of good brand management. Companies that focus on consumer value and manage their brands on this basis find that strong brands follow as a natural result. Companies that emphasise a separate activity called 'brand building' discover that all too often value disappears out of the window.

Brand narcissism has a lot to answer for. Is it infecting your organisation?

\section{Alan Mitchell Editorial Board}

\section{References}

(1) Barwise, P. and Meehan, S. (2004) 'Simply Better', Harvard Business School Press, Boston, MA.

(2) Levitt, T. (1980) 'Marketing success through differentiation - Of anything', Harvard Business Review, Vol. 58, No. 1, pp. 83-91.

(3) Levitt, T. (1986) 'The Marketing Imagination', The Free Press, New York, NY.

(4) Barwise and Meehan, ref. 1 above.

(5) Yankelovich (2004) Marketing Resistance Survey, Yankelovich Monitor OmniPlus Study, Topline Report, 15th April, available from www.yankelovich.com. 